\title{
Treatment of Radiological Medical Waste Using Concrete Cubic Molds
}

\author{
Ali Abdulwahab Ridha ${ }^{1}$, Lara Adnan Kadhim ${ }^{1}$, Basim Abdlsattar Hussain ${ }^{2}$ \\ ${ }^{1}$ Physics Department, College of Science, Mustansiriyah University, Baghdad, Iraq \\ ${ }^{2}$ Ministry of Science and Technology, Directorate of Hazardous Wastes, Baghdad, Iraq
}

Email address:

dr.ali@uomustansiriyah.edu.iq (A. A. Ridha), laraakadhim@yahoo.com (L. A. Kadhim), Basimsaidi@hotmail.com (B. A. Hussain)

\section{To cite this article:}

Ali Abdulwahab Ridha, Lara Adnan Kadhim, Basim Abdlsattar Hussain. Treatment of Radiological Medical Waste Using Concrete Cubic Molds. American Journal of Nanosciences. Vol. 4, No. 3, 2018, pp. 35-39. doi: 10.11648/j.ajn.20180403.12

Received: September 8, 2018; Accepted: October 15, 2018; Published: November 13, 2018

\begin{abstract}
Concrete cubic molds were made and manufactured using a fixed percentage of cement and sand to be as a container for the radiological medical waste in order to prevent radiation during the transfer of radioactive waste from hospitals to their own landfill sites to preserve the safety of people and the environment from radiation pollution. The maximum dose rate was $173.744 \mu \mathrm{Sv} / \mathrm{h}$ in NHTc2 sample measured using RAD EYE B20 dosimeter, which has a very high activity as a medical waste $(28.568 \mu \mathrm{Ci})$, while the lowest dose value $0.297 \mu \mathrm{Sv} / \mathrm{h}$ and activity $0.041 \mu \mathrm{Ci}$ was for MCI4 sample, except the dead samples which less than detection limit for the $\mathrm{NaI}(\mathrm{Tl})$ system. Also, the efficiency calculations of manufactured molds with thickness $3 \mathrm{~cm}$ were done by using Ba-133 and Cs-137 as a point source, because of the energies of these sources are close to that for I-131 and Tc-99 $\mathrm{m}$ exist in the medical waste samples. The shielding percentages were calculated and have very high values with using concrete molds, and the dose rate decreases with increasing the sand in the mold. Measurement of resistivity to compression for the molds were done to acknowledgment the strength to hold radiological waste through transfers or store of these kinds of waste. We found that the increase of the cement percentage (chosen 10, 20 and $30 \%$ ) leads to increasing the mold strength.
\end{abstract}

Keywords: Radiological Medical Waste, Concrete Molds, Dose Rate, NaI(Tl), Rad Eye B20

\section{Introduction}

Radioactive wastes from hospitals form one of the various types of urban wastes, which are managed in developed countries in a safe and organized way. In countries where growth of nuclear medicine services are envisaged, implementations of existing regulatory policies and guidelines in hospitals in terms of handling of radioactive materials used in the treatment of patients need a good model [1]. Although the comparison with other construction materials used in nuclear reactors, concrete has many advantages when it is utilized as a radiation shield, a set of conflicting requirements must be met in the selection of ingredients and mix proportions of concrete designed for the optimum attenuation of both gamma and neutron radiation. For efficient neutron shielding, concrete must contain some heavy elements, which are capable to slow down fast neutrons, and a sufficient quantity of hydrogen to slow down the intermediate and to absorb the slow neutrons. When heavyweight concrete is mixed, placed and consolidated using conventional methods, particular attention should be given to the increasing tendency for mixes to segregate. Standard batching and mixing equipment can be used for high-density concrete. However, the batch sizes should be reduced inversely proportional to densities, as compared with the conventional structural concrete. Radiation shielding concrete must be consolidated to obtain its maximum potential density and to remain free from segregation and entrapped air [2]. Potentially harmful effects of irradiation on the properties of hardened concrete have been investigated for more than 50 years. Some of the results are nonconclusive and others conflicting. One of the reasons seems to be the difficulty of separating the effects of irradiation from the changes, which take place at high temperatures in concrete subjected to high-intensity radiation. Another possible reason is that the extent of damage for a similar exposure varies with the concrete aggregate type and mix composition [3]. when ordinary Portland cement 1 to 3 
mortar, with a water-cement ratio of 0.45 was exposed to the $1012 \mathrm{~cm}^{-2} \mathrm{sec}^{-1}$ neutron flux, there was strength reduction of about $30 \%$ after six months of irradiation. The temperature was maintained constant at about $500^{\circ} \mathrm{C}$. However, further exposure of up to three years produced no additional loss of strength. Companion specimens stored in an oven at $2000^{\circ} \mathrm{C}$ produced a similar decrease in strength. Gamma radiation doses of up to $1010 \mathrm{rd}$ [4]. seem to have no apparent effect on the compressive strength of concrete. In another study, at a gamma-ray dose of $1011 \mathrm{rd}$., reduction of between $25 \%$ and $60 \%$ in concrete strength was reported. Exposure to an integrated flux of between 3 and $8,1019 \mathrm{~cm}^{-2} \mathrm{sec}^{-1}$, resulted in the $31 \%$ strength reduction in barytes mortar, and a $20 \%$ reduction in magnetite mortar [5]. The 100\% leaded glass shields were used half as often (almost as consistently as the thin wall type) and received the highest ratings for a variety of syringe shield characteristics. Lead shield or wrapping with no viewing window was used the least and received the poorest ratings [6]. Technologists who use shields nearly all respondents agreed that shields do significantly reduce radiation exposure. Most agreed that any reduction in exposure is enough to warrant shield use and that shields should be used when injecting doses, preparing radio pharmaceutic, and drawing up doses. There was greater agreement about the use of syringe shields during injection than about their use during preparation and drawing up doses. This is probably because less manipulation of the shield (i.e., reading volumes, removing air bubbles, etc.) is required during injection [7]. However, we have found that higher exposures to the hand occur during preparation and drawing up doses than during injection [8]. Medical applications of radioactive isotopes form one of the important peaceful uses of atomic energy. Unsealed radioactive isotopes are used in hospitals for diagnostic and therapeutic applications in various health disorders. Safe use of radioisotopes in medical applications is the main issue in obtaining clearance from national regulatory authorities. The important issues are 1) safe custody of the received radioisotopes, 2) surveillance for their safe applications in the department and 3) the disposal of the radioactive wastes generated from human use of these radioisotopes. The issues relating to management of radioactive wastes, are very well formulated internationally, and guidelines for radioactive waste disposal are well documented [9-16].

\section{Experimental Part}

\subsection{Templates Preparation}

A number of molds in the shape of a cube have been prepared with fixed percentages of cement and sand in order to prevent radiation during the transfer of radioactive waste from hospitals to their own landfill sites to preserve the safety of people and the environment from radiation pollution. We classified all molds samples into three groups depending on the period of time for dry up the mixing of cement and send as follows:
Group A: Cement was mixed with $10 \%, 20 \%$ and $30 \%$ of the amount of sand used, and 9 molds were made and left for 7 days.

Group B: cement was mixed with $10 \%, 20 \%$ and $30 \%$ of the amount of sand used and made of 9 molds and left for 14 days.

Group C: Cement was mixed with $10 \%, 20 \%$ and $30 \%$ of the amount of sand used and 9 molds were made and left for 28 days. As shown in the table 1 and figure 1.

These molds are designed with different percentages of cement to determine their effect on the blocking ratio. Periods of time are different to determine the resistance of molds to pressure when buried. Therefore, the compression of each group was measured in a laboratory located in the Ministry of Construction and Housing/Construction Section after the work of an important facilitation book to determine the resistance of each set of concrete blocks.

The concrete blocks or cubes have a weight: Cube 10\% Cement $=1827 \mathrm{gm}$, Cube $20 \%$ Cement $=1866 \mathrm{gm}$ and Cube $30 \%$ Cement $=1887 \mathrm{gm}$.

Table 1. Classification of molds in three groups.

\begin{tabular}{llll}
\hline Periods of Time & $\mathbf{1 0 \%}$ Cement & $\mathbf{2 0} \%$ Cement & $\mathbf{3 0 \%}$ Cement \\
\hline Group a & A11 & A21 & A31 \\
(7 days) & A12 & A22 & A32 \\
& A13 & A23 & A33 \\
Group B & B11 & B21 & B31 \\
(14 days) & B12 & B22 & B32 \\
& B13 & B23 & B33 \\
Group C & C11 & C21 & C31 \\
(28 days) & C12 & C22 & C32 \\
& C13 & C23 & C33 \\
\hline
\end{tabular}

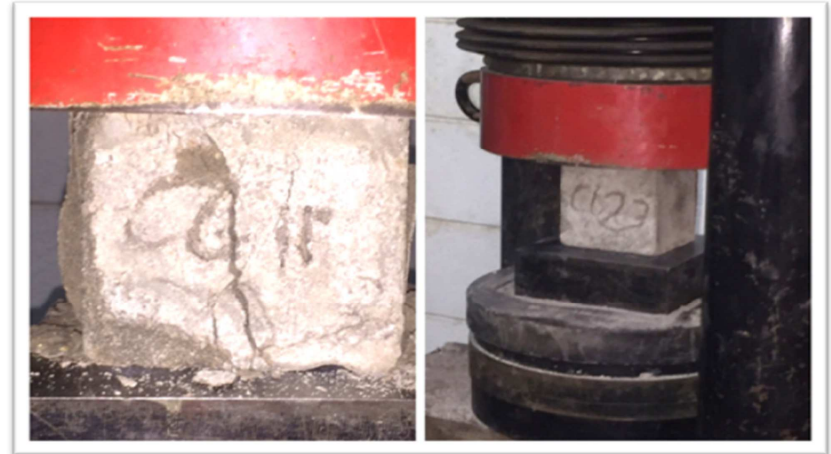

Figure 1. The concrete pattern where ever measuring its resistance by the presses.

\subsection{Dose Measurement in the Templates}

The benefit of the molds is to block the radiation and reduce its rate. The molds were tested using two types of radioactive sources, namely cesium (Cs-137) and barium (Ba-133) because they have energies 81,365 and 662 which are near to that for I-131 and Tc-99 $\mathrm{m}$ used in the present work as a medical waste. Before and after the test, we measured the doses of the radioactive sources using a device Rad Eye B20. The thickness of the designed cube was $3 \mathrm{~cm}$ as shown figure 2 . 


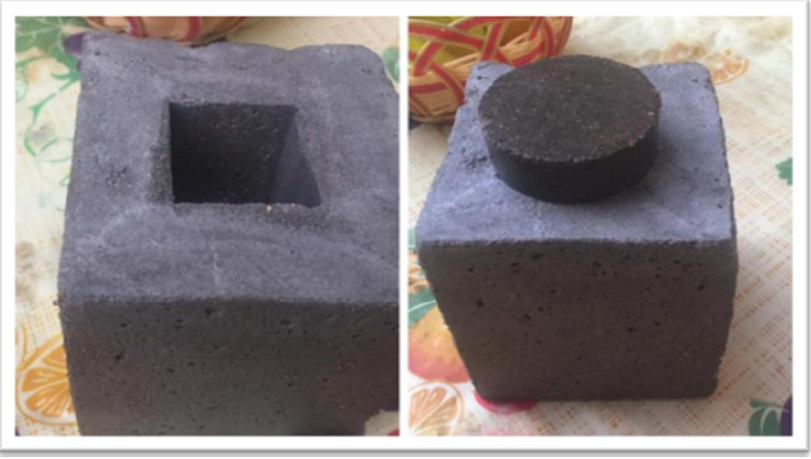

Figure 2. Form of the template in which the dose measurements were done.

\section{Results and Discussion}

Table 2 shows the resistance and compressible of the molds designed to block the radioactivity leaking from the accumulated waste inside the medical center, which has a negative effect on the workers inside the hospitals. The amount of cementation depends on the percentage of cement involved in the manufacture of the concrete mold, using 10 , 20 and $30 \%$ cement with sand has shown to be very sufficient in manufacturing cement-based cubes that can be used for the isolation of radioactive waste. The $10 \%$ cement cubes achieved a compression strength of $55.4 \mathrm{~N} / \mathrm{mm}^{2}$ at 28 days, while $20 \%$ and $30 \%$ cement-based cubes gave a compression strength values of about 80.2 and $159.2 \mathrm{~N} / \mathrm{mm}^{2}$ respectively, which were considered to be above the minimum landfilling waste disposal requirements (NRC, 1991; EPA2014).

It was observed that the cement-based cubes reached about $65-75 \%$ of their maximum strength (Maximum strength is considered to be at 28 days). This goes along with the standard cement C-S-H development and matches many concretes and cement-based mixtures strength development patterns (Michael and John, 1999; Dale et al., 2009). It was observed that the cubes which were manufactured using cement-based mortars can achieve a very solid structure with low permeability and with a rigid structure which can help in their use and utilization as an envelope capsule to contain and hold of different types of waste forms within the manufactured mold.

The $10 \%$ and $20 \%$ cement mold used for blocking of gamma radiation, has a low value comparing with $30 \%$ of the resistance to compression, therefore, we prefer the $30 \%$ cement mixture as optimal type as a function of strength, see the Figure 3.

Table 2. Compression of the concrete blocks depending on time.

\begin{tabular}{llll}
\hline Treatment & $\mathbf{1 0 \%} \mathbf{~ O P C}$ & $\mathbf{2 0} \mathbf{0} \mathbf{O P C}$ & $\mathbf{3 0 \%} \mathbf{\text { OPC }}$ \\
\hline \multirow{2}{*}{ days } & 2.4 & 5.5 & 11 \\
& 2.1 & 5.2 & 11.2 \\
Ave. & 2.2 & 6.3 & 13.3 \\
& 2.2 & 5.7 & 11.8 \\
14 days & 21.1 & 41 & 107.8 \\
& 23.8 & 43 & 110.4 \\
Ave. & 25.8 & 45 & 115.3 \\
& 23.5 & 43 & 111.1 \\
28 days & 50.6 & 76.3 & 156 \\
& 56.3 & 80.8 & 159 \\
Ave. & 59.4 & 83.6 & 162.8 \\
\hline
\end{tabular}

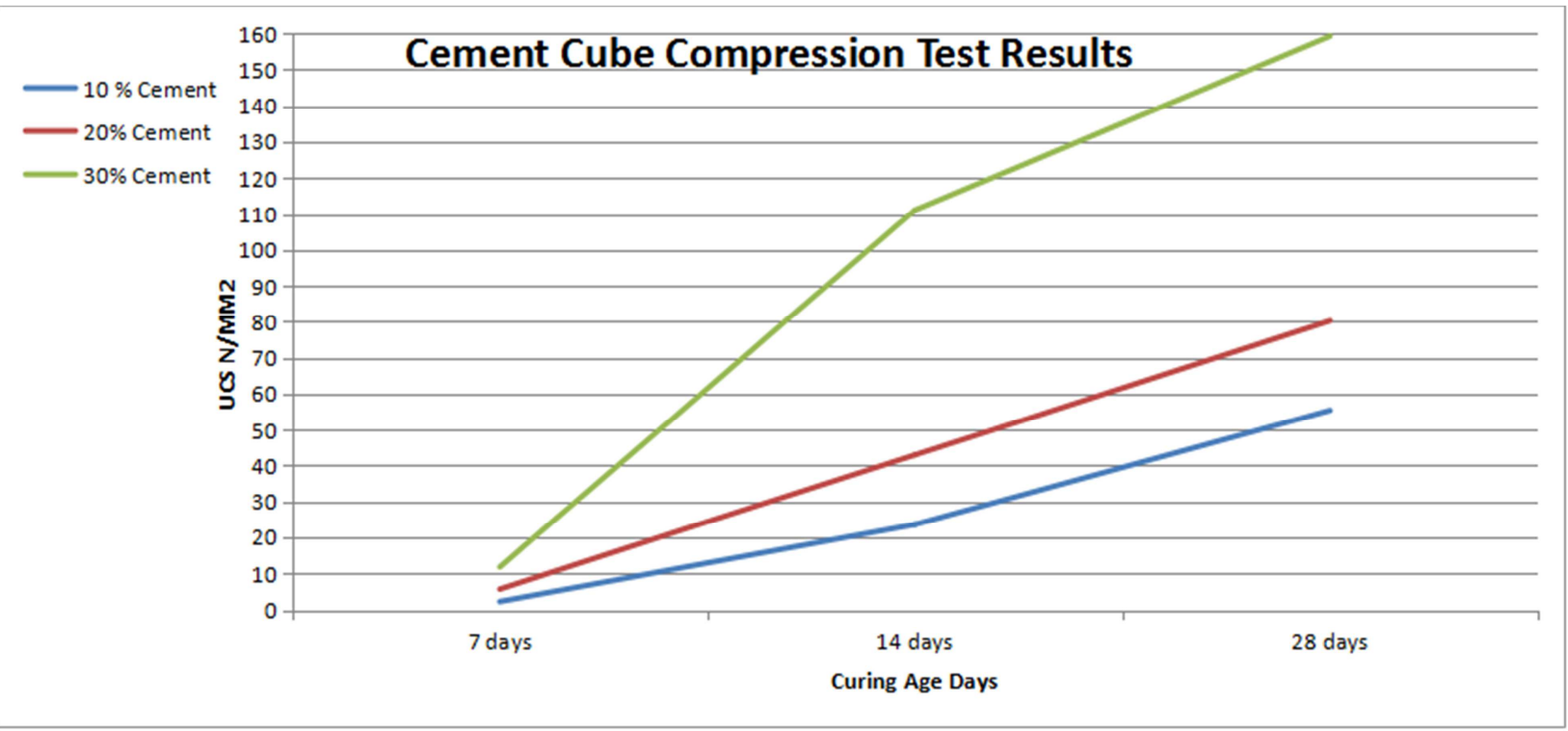

Figure 3. Comparison between different percentages of cement with the curing age. 
Dose Measurement with Mold

To determine the efficiency of the molds in blocking the radiation, isotopes $\mathrm{Ba}-133\left(\mathrm{E}_{\gamma}=365 \mathrm{keV}\right.$ at $\mathrm{I}=62 \%$ and 81 $\mathrm{keV}$ at $33 \%)$ and $\mathrm{Cs}-137\left(\mathrm{E}_{\gamma}=661 \mathrm{keV}\right.$ at $\left.\mathrm{I}=85 \%\right)$ were used because of their energies close to the I-131 $\left(\mathrm{E}_{\gamma}=364.5 \mathrm{keV}\right.$ at $\mathrm{I}=82 \%, 634 \mathrm{keV}$ at $7.16 \%$ and $80.21 \mathrm{keV}$ at $2.62 \%$ ), while Tc-99 $\mathrm{m}(\mathrm{E}=140.5 \mathrm{keV}$ at $\mathrm{I}=89 \%)$ for specific gamma energies.

Table 3 shows the efficiency of the molds in blocking the activity to reduce the radiation leakage from the accumulated radioactive waste. The Dose rate values when putting the barium and cesium isotope inside the molds and checked the dose rate outside as in touch with the mold for a distance of 3 $\mathrm{cm}$ (thickness of the mold) by using Rad Eye B20 dosimeter, were decreases to about $88.2 \%, 87.5 \%$ and $84.7 \%$ for barium to the molds of 10,20 and $30 \%$ cement percentage respectively, while it was decreased to $96.3 \%, 96.2 \%$ and $95.7 \%$ for cesium as a mean value for the three cement percentage, it's clear that the dose rate very decreased from the mean values of the dose rate without using the mold (4.24 and 59.2) $\mu \mathrm{Sv} / \mathrm{h}$ respectively for the same distance between the isotopes and dosimeter in the two cases, as shown in Figure 4. Also, we can find from the Figures 4 and 5 that the blockage of radiation dose rate using the molds were increases with a decrease in the cement percentage. That is because the sand consists of heavy chemical compounds heavier than the chemical compounds involved in cement synthesis. Sand is a mixture of $\mathrm{Si}$ oxides by $70 \%$ and the remainder is $\left(\mathrm{Al}_{2} \mathrm{O}_{3}, \mathrm{Na}_{2} \mathrm{O}, \mathrm{Fe}_{2} \mathrm{O}_{3}\right)$ and others such as potassium and chlorine.

Table 3. Energy and effectiveness of barium and cesium inside and outside the molds.

\begin{tabular}{|c|c|c|c|c|c|c|c|c|}
\hline \multirow{2}{*}{ Isotope } & \multirow{2}{*}{$\begin{array}{l}\text { Activity } \\
(\mu \mathrm{Ci})\end{array}$} & \multicolumn{2}{|c|}{ Dose without molds $(\mu \mathrm{Sv} / \mathrm{h})$} & \multirow{2}{*}{ Cement rate } & \multicolumn{2}{|c|}{ Dose outside molds $(\mu \mathrm{Sv} / \mathrm{h})$} & \multicolumn{2}{|c|}{ Shielding percentage (\%) } \\
\hline & & Max & Mean & & Max & Mean & Max & Mean \\
\hline \multirow{3}{*}{ Ba-133 } & \multirow{3}{*}{0.777} & \multirow{3}{*}{4.61} & \multirow{3}{*}{4.24} & $10 \%$ & 0.60 & 0.50 & 87 & 88.2 \\
\hline & & & & $20 \%$ & 0.71 & 0.53 & 84.6 & 87.5 \\
\hline & & & & $30 \%$ & 0.75 & 0.65 & 83.7 & 84.7 \\
\hline \multirow{3}{*}{ Cs-137 } & \multirow{3}{*}{3.456} & \multirow{3}{*}{63.9} & \multirow{3}{*}{59.2} & $10 \%$ & 2.49 & 2.19 & 96.1 & 96.3 \\
\hline & & & & $20 \%$ & 2.62 & 2.23 & 95.9 & 96.2 \\
\hline & & & & $30 \%$ & 2.77 & 2.52 & 95.7 & 95.7 \\
\hline
\end{tabular}

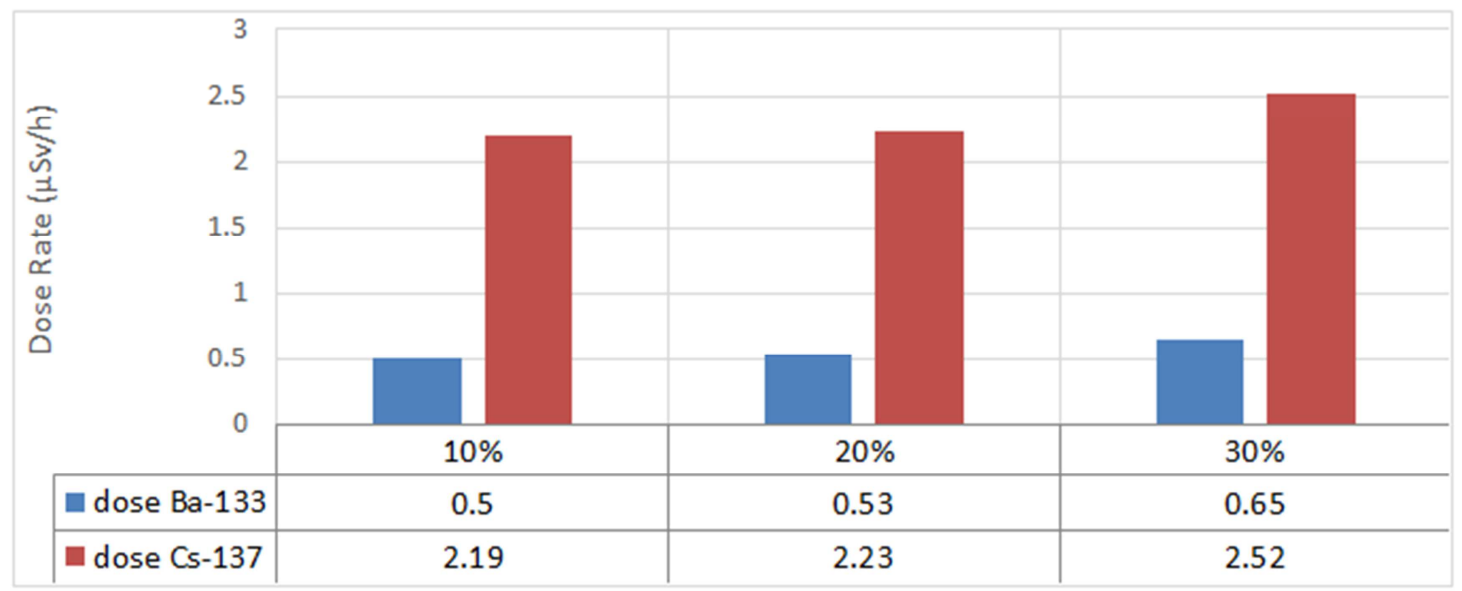

Figure 4. Comparison between the mean dose rate for $\mathrm{Ba}-133$ and $\mathrm{Cs}-137$ with the molds.

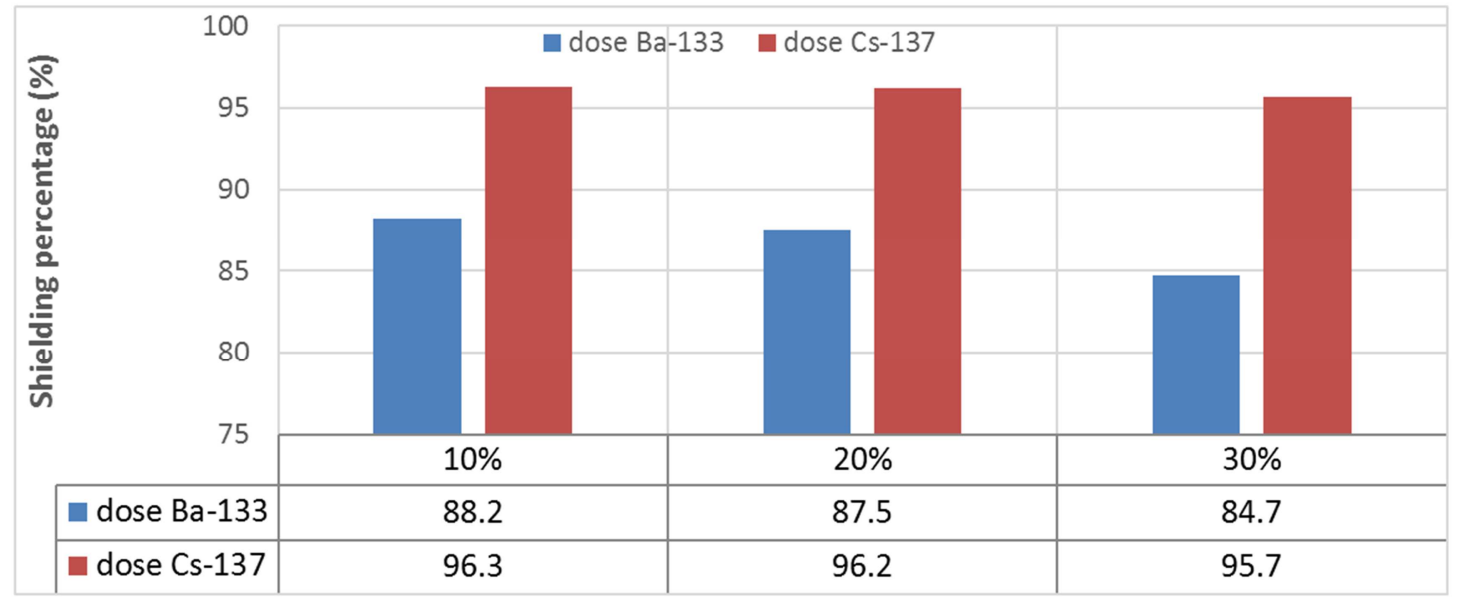

Figure 5. Comparison between the mean dose rate for Ba-133 and Cs-137 with the molds. 


\section{Conclusions}

1. The concrete molds technique supposed in the present work was due to give an alternative treatment for the much radiological waste to less the dose rate at medical centers especially after few times from using to the patients.

2. The increasing in cement percentage in the mold manufactured in the present study gives more strength to the mold but cause a little decrease in the blocking of radiation.

3. The mold very useful to decrease the high amount of radiation and they can be sealed with safety and transport to another store or any other treatment.

\section{Recommendations}

We recommend that, they should be prevention the accumulate of radiological medical waste inside medical centers, specialized in the treatment of cancerous tumors using radioactive materials, due to they cause an increases in external of radiation doses because they contain a radioactivity, even if it is limited, These wastes should be transported to their landfill sites immediately after using, to lessen the side effect of radiation to the workers near the storage areas inside the medical center. Transportation using a concrete container instead of lead is a useful technique in this case because the activity for the waste is small, and the concrete mold is lighter and lessens in cost than lead.

\section{Acknowledgements}

The authors wish to thank radioactivity laboratory at the college of science, Mustansiriyah University for their support.

\section{References}

[1] R. Ravichandran, J. P. Binukumar, Rajan Sreeram and L. S. Arunkumar, An overview of radioactive waste disposal procedures of a nuclear medicine department, J Med Phys, 36(2), pp. 95-99, 2011. doi: 10.4103/0971-6203.79692.

[2] Samarin, A., Use of Concrete as a Biological Shield from Ionizing Radiation, Energy and Environmental Engineering, 1(2), pp. 90-97, 2013.

[3] Batten, A. W. C., Effects of Irradiation on the Strength of Concrete, United Kingdom Atomic Energy Authority, Harwell, 1960.
[4] Alexander, S. C., Effects of irradiation on concrete: final results. K. Harvell, U. K. Atomic Energy Research Establishment, 1963.

[5] Abulfaraj, W. H, and Kamal, S, M, "Evaluation of Ilmenite Serpentine Concrete and Ordinary Concrete as Nuclear Reactor Shielding", Radiation Physics and Chemistry, Elsevier Science Ltd., 44(1/ 2), pp. 139-148, 1994.

[6] Branson BM, Sodd V J, Nishiyama H, et al. Use of syringe shields in clinical practice. Clinical Nuc. Med., 1: 56-59, 1976.

[7] Burr JE, Berg R. Radiation dose to hands from radiopharmaceuticals- Preparation versus injections. J Nuc. Med. Technol., 5: 158-60, 1977.

[8] Ahmed S. N., "Physics and Engineering of Radiation Detection", 1 st edition, Academic Press Inc. Published by Elsevier, Printed and bound in Great Britain, pp. 1-235 2007.

[9] Driver I, Packer S. Radioactive waste discharge quantities for patients undergoing radioactive iodine therapy for thyroid carcinoma. Nucl Med Comm. 2001; 22:1129-32. [PubMed]

[10] Leung PM, Nikolic M. Disposal of therapeutic 131-I waste using a multiple holding tank system. Health Phys. 1998; 10:315-21. [PubMed]

[11] Ravichandran R, Pant GS. Storage and disposal of radioactive waste. In: Pant GS, editor. Radiation Safety of Unsealed Sources. 2 nd ed. Mumbai: Himalaya Pub. Co; 2000. pp. 237 48.

[12] Ravichandran R. Storage and disposal of radioactive waste. In: Pant GS, editor. Radiation safety for unsealed sources. $1 \mathrm{nd}$ ed. Mumbai: Himalaya Pub. Co; 1998. pp. 102-14.

[13] Ravichandran R, Jayasree U, Supe SS, Keshava SL, Devaru S. Abstract P 42. 23 rd IARP Conf. Recent Advances in Radiation Measurements and Radiation Protection, Amristar, Feb. 1997.

[14] Soman SD, Venkateshwaran TV. Radiological protection aspects of radionuclide therapy for cancer of the thyroid. Proc. of Seminar, Bombay, 4-6 March 1998, BARC, Bombay. Sponsored by BARC and WHO; 1998. pp. 195-202.

[15] Thayalan K, editor. Radioactive waste disposal. In Text Book of Radiological Safety. Chennai: Jaypee Med Publication; 2010. p. 267. p. 88.

[16] Applying radiation safety standards in Nuclear Medicine. Safety Reports Series No.40. Vienna: IAEA; 2005. 